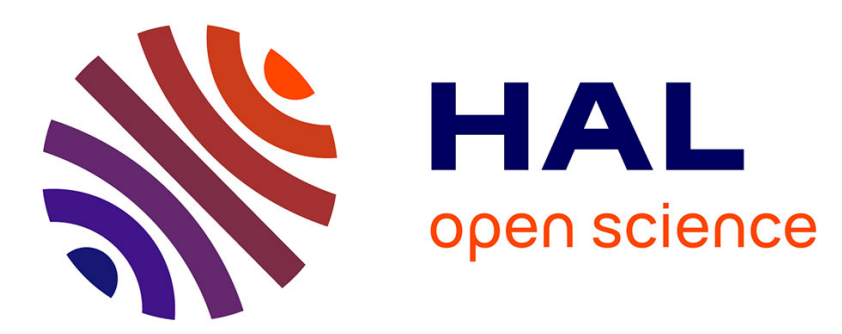

\title{
Work-of-indentation coupled to contact stiffness for calculating elastic modulus by instrumented indentation
}

Michel Yetna N'Jock, Francine Roudet, I. Idriss, Olivier Bartier, Didier Chicot

\section{To cite this version:}

Michel Yetna N'Jock, Francine Roudet, I. Idriss, Olivier Bartier, Didier Chicot. Work-of-indentation coupled to contact stiffness for calculating elastic modulus by instrumented indentation. Mechanics of Materials, 2016, 94, pp.170-179. 10.1016/j.mechmat.2015.12.003 . hal-01259824

\section{HAL Id: hal-01259824 \\ https://hal.science/hal-01259824}

Submitted on 4 Feb 2016

HAL is a multi-disciplinary open access archive for the deposit and dissemination of scientific research documents, whether they are published or not. The documents may come from teaching and research institutions in France or abroad, or from public or private research centers.
L'archive ouverte pluridisciplinaire HAL, est destinée au dépôt et à la diffusion de documents scientifiques de niveau recherche, publiés ou non, émanant des établissements d'enseignement et de recherche français ou étrangers, des laboratoires publics ou privés. 


\section{Highlights}

$>$ Instrumented indentation is performed on various metals and alloys.

$>$ Frame compliance of the instrument is taking into account for accurate measurements.

$>$ A new relationship between the elastic recovery energy to the total work-of-indentation ratio and the applied load to the square of the contact stiffness ratio is proposed.

$>$ A proportionality factor has been found by both finite elements method and inverse analysis for the material presenting an intermediate mechanical behavior.

$>$ The values of elastic modulus obtained from the new relationship are in a very good agreement with the theoretical values given in literature. 


\title{
Work-of-indentation coupled to contact stiffness for calculating elastic modulus by instrumented indentation
}

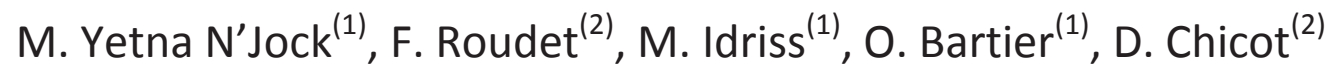 \\ (1) Université Rennes 1, LGCGM-INSA Rennes, 20 avenue des buttes de Coësmes, CS 14315, F-35043 \\ Rennes, France. \\ (2) Université Lille Nord de France, Lille1, LML, UMR 8107, F-59650 Villeneuve d'Ascq, France.
}

Corresponding author:

E-mail address:
Michel Yetna N'Jock

michel.yetna-njock@insa-rennes.fr

\section{Abstract}

Elastic modulus of a large variety of materials: low-carbon steel, rolled and rapid prototyping stainless steels, aluminum, brass, beta tricalcium phosphate ( $\beta$-TCP) bioceramic) and the $\mathrm{TiB}_{2}-60 \% \mathrm{~B}_{4} \mathrm{C}$ composite ceramic were determined by Vickers instrumented indentation tests. A relationship the ratio of elastic recovery energy to total work-of-indentation and the product of the maximum applied load and the square of the contact stiffness is proposed to assess the elastic modulus of materials. A proportionality factor $\kappa$ defining pile-up or sink-in behavior has been validated by both the Finite Element (FE) analysis and inverse method for a material presenting an intermediate mechanical behavior. Values obtained for elastic modulus agree satisfactorily with theoretical values found in literature. The main advantage of the proposed relationship in the determination of the elastic modulus is that it does not require the computation of the contact area between the indenter and the material which is often at the origin of uncertainties.

\section{Keywords}

Work-of-indentation; Elastic modulus; Finite Elements analysis method.

\section{Introduction.}

Instrumented indentation technique is widely used for the determination of the mechanical properties of materials for which many methodologies exist to assess all these properties. From a load-displacement curve (Zeng and Chiu, 2001), two distinct methods for calculating hardness and elastic modulus can be applied, i.e. the conventional method and work-of-indentation method. From a general point of view, the conventional method allows the computation of the hardness from the maximum load and a representative contact area between the indenter and the material (Collin et al., 2008; Alcala et al., 2000; Bartier et al., 2010) while the elastic modulus is determined from the 
analysis of the unloading part of the load-displacement curve (Bulychev et al., 1975 ; Loubet et al., 1984; Doerner and Nix, 1986). The work-of-indentation method bases the mechanical properties determination on the energy required to create a unit volume of deformation (Sakai et al., 1993; Malzbender et al., 2005). The hardness is then defined by the ratio between the total or plastic workof-indentation and the total or the residual impression volume obtained after the complete withdrawal of the indenter, while the elastic modulus depends on the hardness to elastic recovery energy ratio. Both deformation modes around the indent can occur for Vickers indentation of materials. In some cases, there is an upward extrusion of displaced material (pile-up mode). In the other situations, there is a tendency for the material to be depressed around the indentation (sink-in mode). These phenomena depend on the elastic modulus to the yield stress ratio and on the strain hardening exponent of the indented material (Alcala et al., 2000), on the friction coefficient (Mata et al., 2004) and on the residual stress into the material (Bolshakov et al., 1996). Usually, the conventional method necessitates the knowledge of the deformation mode around the indent as well as the contact area between the indenter and the material which must be well-defined for a precise determination of the properties. Indeed, the definition of the contact depth is connected to the deformation mode, i.e. the methodology of Oliver and Pharr (1992) must be applied when the sink-in mode of deformation is observed whereas the methodology of Loubet et al. (1993) is adequate when pile-up is formed. Moreover in the two cases, the influence of the tip defect must be taken into account for the computation of the contact area. For that, different calibration functions have been developed for which their accuracy depends on the scale of measurement. For example, the relation of Loubet et al. (1993) that consists in adding the length of the truncated indenter tip to the contact depth is applicable for indenter displacements higher than approximately 100 - $200 \mathrm{~nm}$ depending on the magnitude of the tip defect. On the other hand, the complex polynomial function proposed by Oliver and Pharr (1992) which is without any doubt the most precise function is commonly applied in nanoindentation with the continuous stiffness measurement mode. An alternative function has been proposed by Chicot et al. (2014) to be relevant from $10 \mathrm{~nm}$ in-depth with only one fitting parameter which is the truncated tip defect length.

The objective of this paper is to propose an alternative method based on the work-of-indentation which does not require the computation of the contact area when the deformation mode around the indenter is known. To validate the proposed methodology, instrumented microindentation tests using a Vickers indenter were performed on several materials presenting different mechanical behaviors: low-carbon steel, rolled and rapid prototyping stainless steels, aluminum, brass, beta 
tricalcium phosphate ( $\beta-T C P)$ bioceramic and the $\mathrm{TiB}_{2}-60 \% \mathrm{~B}_{4} \mathrm{C}$ composite ceramic.

\section{Theoretical background.}

\subsection{Conventional method.}

The general definition of the hardness, $H$, is the ratio between the maximum load, $P_{\mathrm{m}}$, and a representative area of the contact between the indenter and the material, $A$ :

$$
H=\frac{P_{m}}{A}
$$

Where $A$ can be denoted by $A_{R}$ when considering the true contact area and $A_{C}$ when it designates the projected one in the plane of the indented surface.

The reduced elastic modulus $E_{\mathrm{R}}$ is calculated from the slope of the unloading part of a load-depth curve, $1 / C$, and the contact area $A_{C}$ by applying the methodology developed by Oliver and Pharr (1992) as follows:

$$
E_{R}=\frac{\sqrt{\pi}}{2} \cdot \frac{1}{\beta \gamma} \cdot \frac{1}{\left(C_{T}-C_{f}\right)} \cdot \frac{1}{\sqrt{A_{C}}}
$$

Where $\beta$ is a corrective factor introduced by Bulychev et al. (1975). A three dimension analysis of Vickers indentation performed on various materials ranging a large area of mechanical properties (yield stress, work hardening exponent and modulus of elasticity) leads to a value of

$\beta$ close to 1.05. $\gamma$ is a factor depending on the Poisson's ratio introduced by Hay et al. (1999) to consider the elastic radial displacement neglected in the formulation of Sneddon. $C_{T}$ is the total compliance taking into account both the compliance of the tested sample and the compliance of the load frame of the instrument, $C_{\mathrm{f}} . E_{R}$ includes both the indenter parameters $\left(E_{\mathrm{i}}, v_{\mathrm{i}}\right)$ and the investigated material parameters $(E, v)$ in the following relation:

$$
\frac{1}{E_{R}}=\frac{1-v^{2}}{E}+\frac{1-v_{i}^{2}}{E_{i}}
$$

It can be noted from Eq. (1) and Eq. (2) that for a precise determination of hardness and elastic modulus parameters, the contact area must be accurately determined. This is achievable from numerical and experimental approaches (Hay et al., 1999). To take into account the influence of the tip defect and for indenter displacement higher than a value approximately around $100-200 \mathrm{~nm}$, the model of Loubet et al. (1993) and confirmed by Troyon and Huang (2006) is consistent enough. 
Compared to the contact area calculated for a perfect indenter tip, this model only consists in adding the length of the truncated indenter tip to the contact indenter displacement:

$$
A_{C}=24.56 \cdot\left(h_{c}+h_{b}\right)^{2}
$$

Where $h_{\mathrm{c}}$ is the contact depth and $h_{\mathrm{b}}$ the truncation length of the tip defect.

In nanoindentation when using the continuous stiffness measurement mode, Oliver and Pharr (1992) suggest the use of the following complex area function:

$$
A_{C}=24.56 \cdot h_{c}^{2}+C_{1} \cdot h_{c}^{1}+C_{2} \cdot h_{c}^{1 / 2}+C_{3} \cdot h_{c}^{1 / 4}+\ldots+C_{8} \cdot h_{c}^{1 / 128}
$$

Where $C_{1}$ through $C_{8}$ are constant fitting parameters.

The leading term describes a perfect pyramidal indenter which can be sometimes also considered as a free parameter; the others describe deviations from the conical geometry due to the bluntness of the indenter tip. To reduce the number of constants and to provide them a physical meaning, numerous contact area functions have been proposed based on polynomials of second degree depending on the contact depth (Chicot et al., 2014). To avoid the introduction of fitting parameters or to reduce them, Chicot et al. (2014) proposed the following relation:

$$
A_{C}=24.56 \cdot\left(h_{c}+h_{b} \cdot\left(1-\exp \left[-2 \frac{h_{c}}{h_{b}}\right]\right)^{3 / 2}\right)^{2}
$$

Where $h_{\mathrm{b}}$ can be determined by regression analysis of the experimental data or estimated from microscopic observations at very high magnifications.

Additionally to take into account the deformation mode around the indent, i.e. the sink-in deformation mode or the pile-up deformation mode, the contact depth can be calculated using the methodology of Oliver and Pharr (1992) or the methodology of Loubet et al. (1993), respectively. According to the methodology, the contact depth is expressed as follows:

- For sink-in, $\quad h_{c}=h_{m}-0.75 \cdot P_{m} \cdot C_{T}$

- For pile-up, $\quad h_{c}=1.2\left(h_{m}-P_{m} \cdot C_{T}\right)$

Where $h_{\mathrm{m}}$ is the maximum indentation depth and $P_{\mathrm{m}}$ the maximum indentation load. $C_{T}$ is the total compliance equals to the reciprocal slope of the unloading part of the load-depth curve.

To identify the mode of deformation around the indent, Yetna et al. (2015) have proposed a criterion 
based on the residual indenter depth to maximum indentation displacement ratio. When this ratio is lower than 0.83 , the sink-in mode is predominant whereas the pile-up deformation mode occurs when this ratio is higher than this limit value of 0.83 .

As a conclusion for obtaining consistent values for the mechanical properties, a rigorous methodology must be followed since it is necessary to take into account the frame compliance of the instrument, the bluntness of the indenter tip and the deformation mode around the indent because these parameters can affect in a great extent the computation of the mechanical properties. Indeed, Alcala et al. (2000) mentioned that errors up to $30 \%$ can be introduced in the computation of the contact area if the deformation mode is not taken into account. Moreover, when the compliance term is not introduced in Eq. (2), the elastic modulus varies as a function of the contact area. If the compliance term is considered as a constant value in nanoindentation, this term has been found dependent on the indentation conditions in microindentation. Consequently, it must be absolutely determined for each series of indentation tests in this range of micro-loads, (Chicot et al., 2011). However, even if corrections have been carefully made in order to take into account the bluntness of the indenter tip (Hochstetter et al., 1999) and the frame compliance (Oliver and Pharr, 2004), the mechanical properties can slightly differ in comparison to the theoretical values due to the modes of deformation (O'Neil, 1951) which affects the calculation of the contact area. This has motivated this study on the determination of the elastic modulus from the work-of-indentation in order to circumvent the problems mentioned here-above.

\subsection{Work-of-indentation.}

Considering the energetic approach, Stillwell and Tabor (1961) express the hardness as the work-ofindentation divided by the impression volume. Sakai (1993) specifies this definition accordingly to the mechanical behavior of the material. For rigid plastic materials, this is the total hardness, $H_{\mathrm{T}}$, which is defined by the total energy, $U_{\mathrm{T}}$, divided by the total volume of the impression, $V_{\mathrm{T}}$. For elastic/plastic materials, the author suggested the computation of a plastic hardness, $H_{p}$, which is defined as the plastic work-of-indentation, $U_{P}$, and the residual impression volume, $V_{P}$, ratio obtained after the complete withdrawal of the indenter. Figure 1 schematically represents the regions of the total workof-indentation and the elastic energy on a load-depth curve considered in the calculations. 


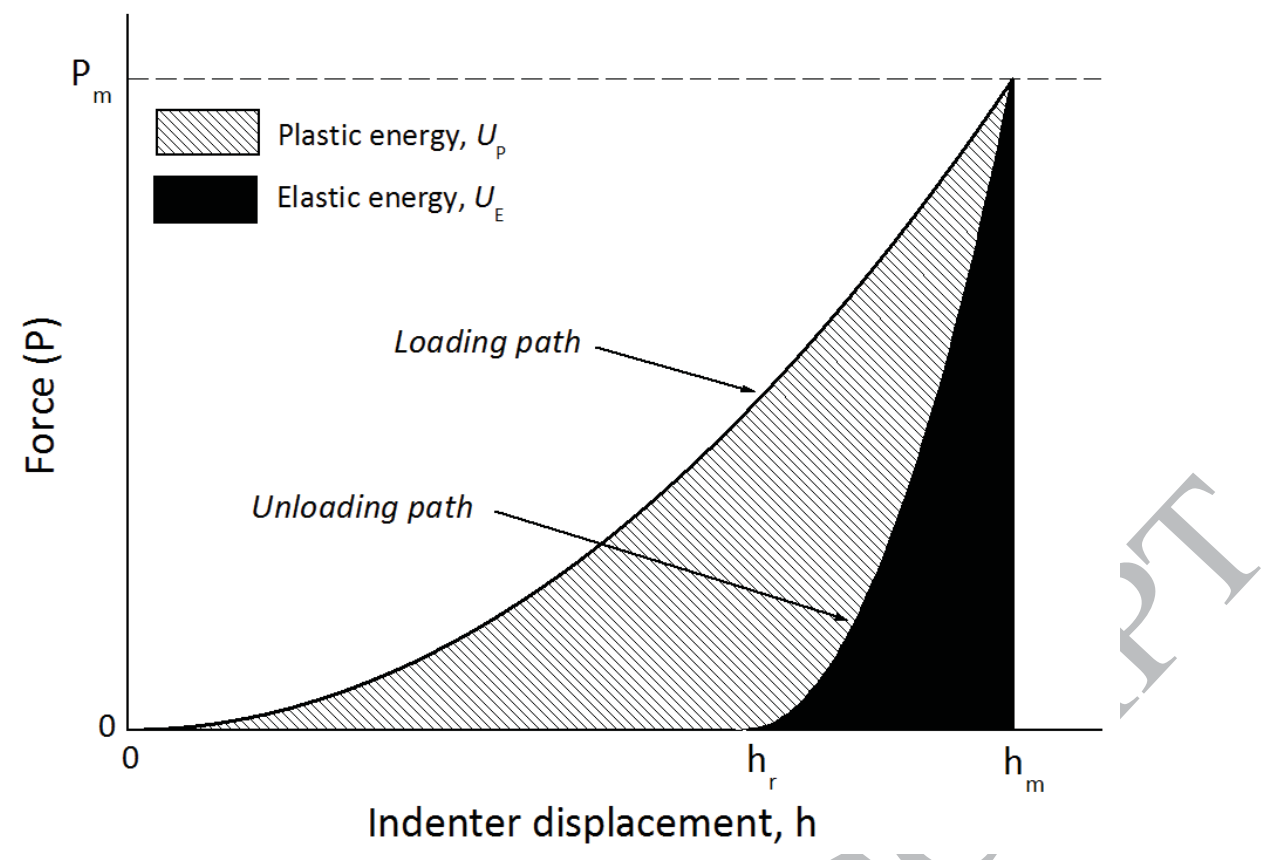

Figure 1. Identification of the plastic and elastic work-of-indentation on a load-displacement curve obtained from instrumented indentation test.

On a load-displacement curve (Fig. 1), a power-law is usually applied for representing the loading and the unloading paths (Zeng and Chiu, 2001). The general relationships are respectively given by:

$$
\begin{aligned}
& P_{L}=B \cdot h^{n} \\
& P_{U}=D \cdot\left(h-h_{r}\right)^{m}
\end{aligned}
$$

Where $P_{\mathrm{L}}$ and $P_{\cup}$ relate to the force of the loading and unloading paths, respectively. $B, D, n, m$ and $h_{\mathrm{r}}$ are fitting parameters.

Based on these equations, the total work-of-indentation, $U_{T}$, caused by the indenter in deforming the material, is calculated from the whole area under the loading path of a load-displacement curve. $U_{T}$ is then defined by the following relation:

$$
U_{T}=\int_{0}^{h_{m}} B \cdot h^{n} \cdot d h=\left(\frac{B}{n+1}\right) \cdot h_{m}^{n+1}
$$

For the computation of the plastic hardness, the plastic work-of-indentation $U_{\mathrm{p}}$ is calculated from the areal difference between the total work-of-indentation, $U_{T}$, and the elastic recovery energy, $U_{E}$, corresponding to the area located under the unloading path of the load-displacement curve:

$$
U_{p}=U_{T}-U_{E}=U_{T}-\int_{h_{r}}^{h_{m}} D \cdot\left(h-h_{r}\right)^{m} \cdot d h=\left[\left(\frac{B}{n+1}\right) \cdot h_{m}^{n+1}\right]-\left[\left(\frac{D}{m+1}\right) \cdot\left(h_{m}-h_{r}\right)^{m+1}\right]
$$


For rigid plastic materials, $V_{\mathrm{T}}$ is equivalent to the volume of a cone calculated at the maximum indentation depth. The half-angle of the equivalent conical indenter for a Vickers indenter is $\theta=$ $70.3^{\circ}$. Thus, $V_{\mathrm{T}}$ can be calculated by:

$$
\mathrm{V}_{\mathrm{T}}=\frac{\mathrm{A} \cdot \mathrm{h}_{\mathrm{m}}}{3}=\frac{\pi}{3} \cdot \tan ^{2} \theta \cdot \mathrm{h}_{\mathrm{m}}^{3}
$$

For the computation of the plastic volume $V_{\mathrm{P}}$, Sakai (1993) simply suggested that $V_{\mathrm{P}}$ and $V_{\mathrm{T}}$ are directly proportional to the residual depth, $h_{r}$, to the maximum depth, $h_{m}$, ratio as follows:

$$
\mathrm{V}_{\mathrm{P}}=\mathrm{V}_{\mathrm{T}} \cdot \xi \text {, with } \xi=\frac{\mathrm{h}_{\mathrm{r}}}{\mathrm{h}_{\mathrm{m}}}
$$

In order to take into account simultaneously the influence of the deformation mode around the indent and the influence of the tip defect into the calculation of $V_{T}, \operatorname{Tan}(2006)$ proposed to modify Eq. (11) by introducing the contact area model of Malzbender et al. (2000), i.e. the truncated length of the rounded indenter tip, $h_{\mathrm{b}}$, is added to the indenter displacement, and the maximum depth is replaced by the contact indentation depth defined by Oliverand Pharr (1992) or Loubet et al. (1993) according to the mode of deformation, sink-in or pile-up, respectively:

$$
\mathrm{V}_{\mathrm{T}}=\frac{\pi}{3} \cdot \tan ^{2} \theta \cdot\left(\mathrm{h}_{\mathrm{c}}+\mathrm{h}_{\mathrm{b}}\right)^{3}
$$

Based on numerical simulations realized between the elastic recovery energy to the total work-ofindentation ratio and the hardness to the reduced elastic modulus ratio, numerous studies (Malzbender, 2005 ; Alkorta et al., 2006 ; Yang et al., 2008 ; Chen and Bull, 2009 ; Yang et al., 2010) propose the following linear relationship:

$$
\frac{U_{E}}{U_{T}}=1-\frac{U_{P}}{U_{T}}=\kappa \cdot \frac{H}{E_{R}}
$$

The proportionality factor $\kappa$ has been reported as a single value of around 5.0 independently of the work-hardening behavior from indentation when it is performed with a conical indenter having a half-included angle of 70.3 (Malzbender, 2005 ; Alkorta et al., 2006 ; Yang et al., 2008 ; Chen and Bull, 2009 ; Yang et al., 2010). However, FEM (finite element method) achieved by Choi et al. (2004) show that $\kappa$ depends on the value of the ratio $\left(U_{E} / U_{T}\right)$ as it is clearly visible in Fig. 2. 


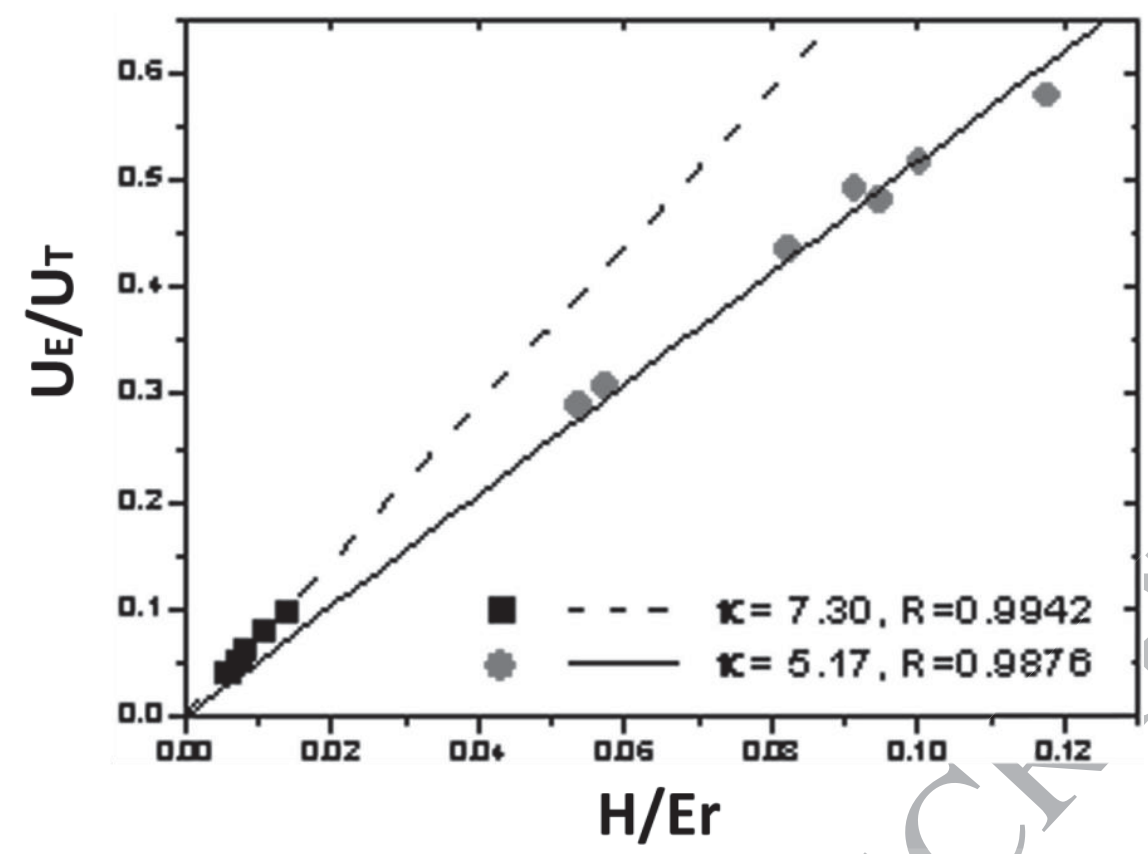

Figure 2. Relation between $U_{E} / U_{T}$ and $H / E_{R}$ in finite elements analysis (Choi et al., 2004).

It is observed in Figure 2 that the parameter $\kappa$ is equal to 5.17 when $\left(U_{E} / U_{T}\right)$ is higher than approximately 0.25 whereas it is equal to 7.30 for values of $\left(U_{E} / U_{T}\right)$ lower than 0.15 . Choi et al. (2004) add that this change of the value of $\kappa$ is related to the competitive phenomenon between pile-up formation and elastic deflection of the materials. א equals 7.30 when pile-up occurs and it equals 5.17 for the sink-in deformation mode. Nevertheless, Figure $\mathbf{2}$ shows no experimental data in the middle region, i.e. when $\left(U_{\mathrm{E}} / U_{\mathrm{T}}\right)$ is between 0.15 and 0.25 , consequently no information is given to estimate the value of $\kappa$ between 7.30 and 5.17 .

On the other hand, it is clear that the computation of the reduced modulus from Eq. (14) greatly depends on the accuracy of the parameter $\kappa$. Moreover, no clear definition is given about the hardness that must be used in this calculation. This is an important point because, for example, Tan (2006) found a difference between the hardnesses HT or HP deduced from the work-of-indentation and the hardness HIT calculated by the methodology of Oliver and Pharr (1992) with an amplitude which seems to be dependent on the mechanical properties of the material. The present work proposes to implement a similar approach in order to compare the reduced modulus calculated from Eq. (14) to the literature one when the classical hardness, HIT, and the plastic hardness, HP, are considered. The plastic hardness HP relates the plastic volume directly proportional to the impression volume, $V_{\mathrm{T}}$, proposed by Tan (2006) and the ratio between the residual indentation depth $h_{\mathrm{r}}$ and the total depth at the maximum load $h_{\mathrm{m}}$ as follows: 


$$
H P=\frac{U_{P}}{\left[\frac{\pi \cdot \tan ^{2} \theta}{3} \cdot\left(h_{c}+h_{b}\right)^{3}\right] \cdot\left(\frac{h_{r}}{h_{m}}\right)}
$$

To avoid any confusion in the rest of this work, the reduced modulus in Eq. (14) is denoted as $E_{\mathrm{IT}}$ when the hardness considered is HIT whilst it is denoted $E_{\mathrm{p}}$ when considering HP.

\section{Experiments and simulations process.}

\subsection{Experiments.}

Instrumented indentation tests have been performed using the CSM2-107 microhardness tester. Seven materials presenting different behavior: low-carbon steel, aluminum, brass, beta tricalcium phosphate ( $\beta$-TCP) bioceramic, stainless steel (SS) and rapid prototyping stainless steel (RPSS) and ceramic composite $\mathrm{TiB}_{2}-60 \% \mathrm{~B}_{4} \mathrm{C}$ have been tested. The manufacturing conditions and additional details on these materials can be found in (Yetna et al., 2015). Vickers indenter was used for each sample analysis with maximum loads ranging from $50 \mathrm{mN}$ to $15 \mathrm{~N}$. At least 20 tests were performed in this range. In addition, a dwell-time of $15 \mathrm{~s}$ was imposed at the maximum applied load according to the standard CSM test procedure. Loading and unloading rates (in $\mathrm{mN} / \mathrm{min}$ ) have been set up at twice the value of the maximum applied load according to Quinn et al. (2002). The tip defect of the indenter was evaluated using the HITACHI field emission scanning electron microscope of type S-4300 $\mathrm{SE} / \mathrm{N}$. The measurement of the tip defect gave $150 \mathrm{~nm}$ for the Vickers indenter (Chicot et al., 2013). The compliance term of the instrument was determined for each series of indentation test and afterwards introduced into the indentation data for obtaining accurate values of the mechanical properties.

\subsection{Finite Elements Analysis.}

An axisymmetric two-dimensional finite-element model was constructed to simulate the indentation response of elastoplastic rapid prototyping stainless steel (RPSS) using the commercial software ABAQUS (2003). The material properties used in the simulation have been identified by inverse analysis method described in the following section. A total of 9178 nodes and 8876 axisymmetric linear quadrilateral elements of type CAX4R were used. A fine mesh near the contact region becoming gradually coarser further from the contact region was designed to ensure numerical accuracy (Fig. 3). The simulation was performed under friction contact conditions $(\mu=0.1)$ using the large strain elastic-plastic feature of the ABAQUS finite element code. The constitutive model of the indented 
material was taken to follow the well-known J2-associated flow theory with rate-independent deformation and isotropic hardening. Yielding occurs according to the Von Mises's criterion and the stress-strain relationship follows the piecewise linear/power-law:

$\sigma=\left\{\begin{array}{c}E \varepsilon \quad \text { if } \quad \sigma \leq \sigma_{Y} \\ \sigma_{Y}^{(1-n)} E^{n} \varepsilon^{n} \quad \text { if } \quad \sigma>\sigma_{Y}\end{array}\right.$

Where $\varepsilon$ is the total strain, $\sigma$ is the stress, $\mathrm{E}$ is the Young modulus, $\sigma_{\mathrm{Y}}$ is the yield stress and $\mathrm{n}$ is the strain hardening exponent.
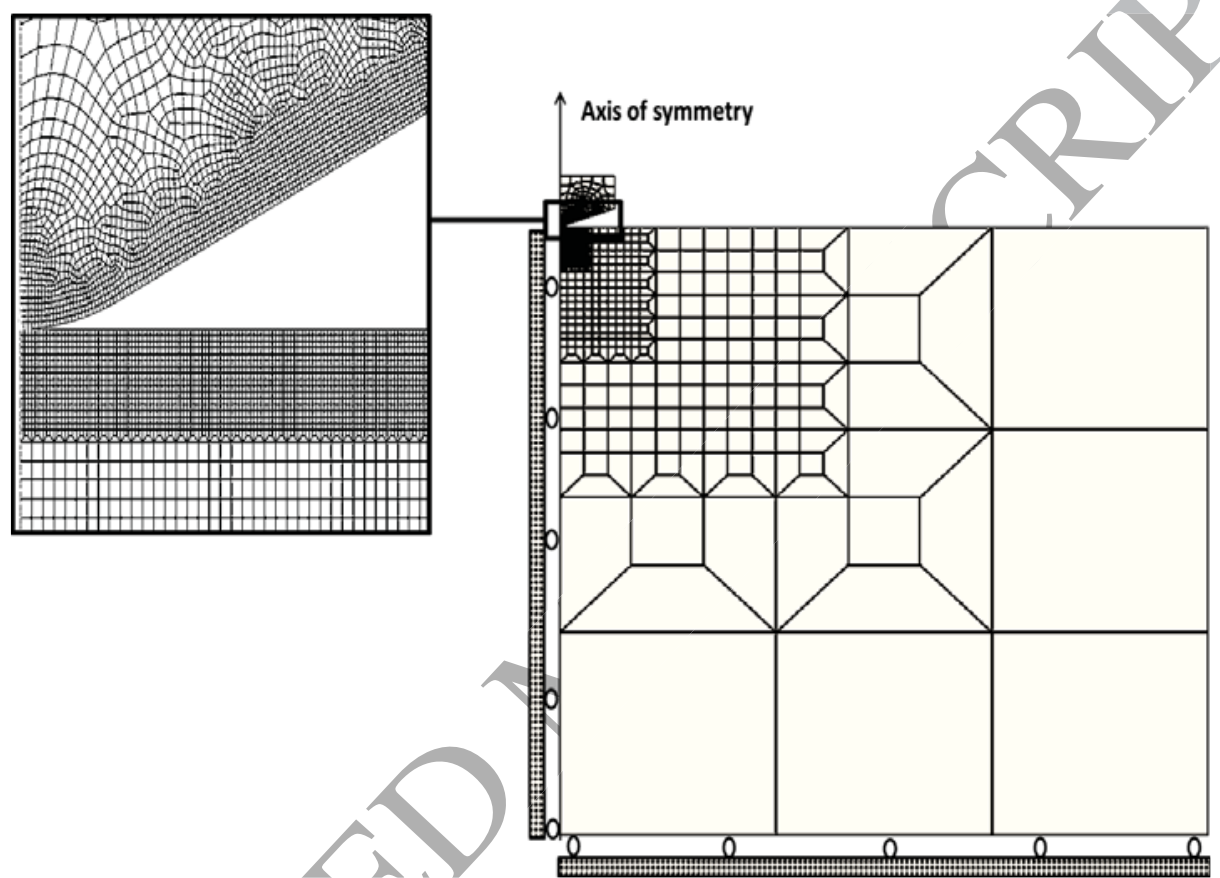

Figure 3. Finite Element model for Vickers instrumented indentation simulation.

The indenter was modeled as a non-rigid cone of a semi-vertical angle $70.3^{\circ}$ with properties $1141 \mathrm{GPa}$ and 0.07 for the elastic modulus and Poisson's ratio, respectively. As it was mentioned previously, the indenter tip presents a tip defect $h_{b}$ of $150 \mathrm{~nm}$. Therefore, the cone tip has been modeled as a smoothed tip by a sphere of radius, $R$ equals to $4215 \mathrm{~nm}$. A displacement was imposed on the indenter, causing it to be pushed into the surface of the material to $2248.2 \mathrm{~nm}$ maximum depth to simulate the indentation process. The loading and unloading curves were obtained directly from the ABAQUS output of the total reaction force in the normal direction on the non-rigid indenter as a function of the vertical top indenter displacement. Real contact area was obtained directly from ABAQUS output after the unloading step.

\subsection{Inverse analysis technique}


For identifying the work hardening law of the RPSS material, the mode FRONTIER software has been used for the inverse analysis calculation. This technique consists in the use of a cost functional to quantify the difference between the finite element simulation and the experimental measurements in order to find out the required parameters. The proposed method is divided into three stages. First the experiment is performed and then modeled by the finite element method using initial mechanical values of oy and $n$ which were randomly chosen for the material model (Fig. 4). The initial mechanical parameters are implemented in the finite element model using user subroutine UHARD. The simplex minimization algorithm is used in order to minimize the difference between the experimental curve and the numerical one. The identification problem consists in determining oy and n. Finally, material parameters are determined when the minimized value of the cost functional is reached.

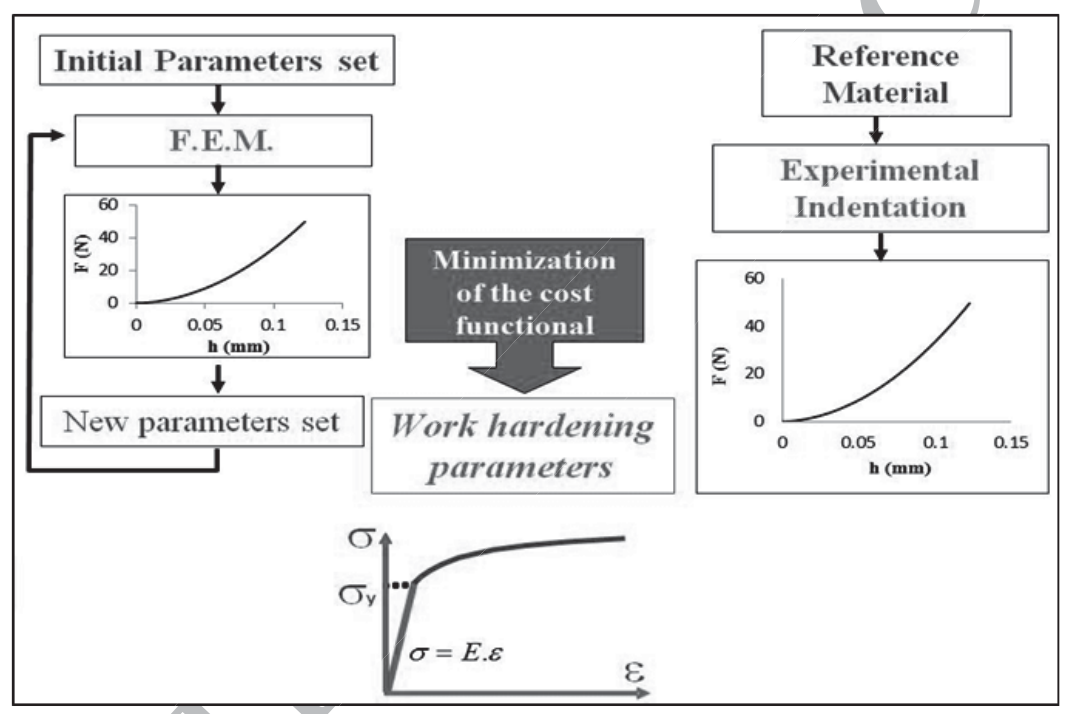

Figure 4. Schema of the inverse analysis technique applied to the instrumented indentation test.

The cost functional is written in the following form:

$$
E_{1}\left(\frac{h_{m}}{R}\right)=\frac{1}{h_{m}} \int_{0}^{h_{m}}\left(F_{\text {ref }}-F_{\text {num }}\right)^{2} \cdot d h
$$

Where $h$ is indenter displacement, $h_{\mathrm{m}}$ is the maximum penetration, $F_{\text {ref }}$ is the experimental load obtained for the tested material and $F_{\text {num }}$ is the numerical load obtained with the FE code.

The calculation stops when one of the convergence criteria is reached. The convergence criterion of the inverse analysis calculation is the value of the variation of the cost functional. Whenever this last value is lower than $10^{-8} \mathrm{~N}^{2}$, the calculation stops and it is considered that the computation has converged to an optimal solution. 


\section{Results and discussion.}

\subsection{Experimental results.}

The load-indenter displacement curves using a Vickers indenter obtained for the aluminum 6061-T6 are shown in Figure $\mathbf{5}$ as an example. Note that the same reproducibility during the loading are obtained for each tested sample.

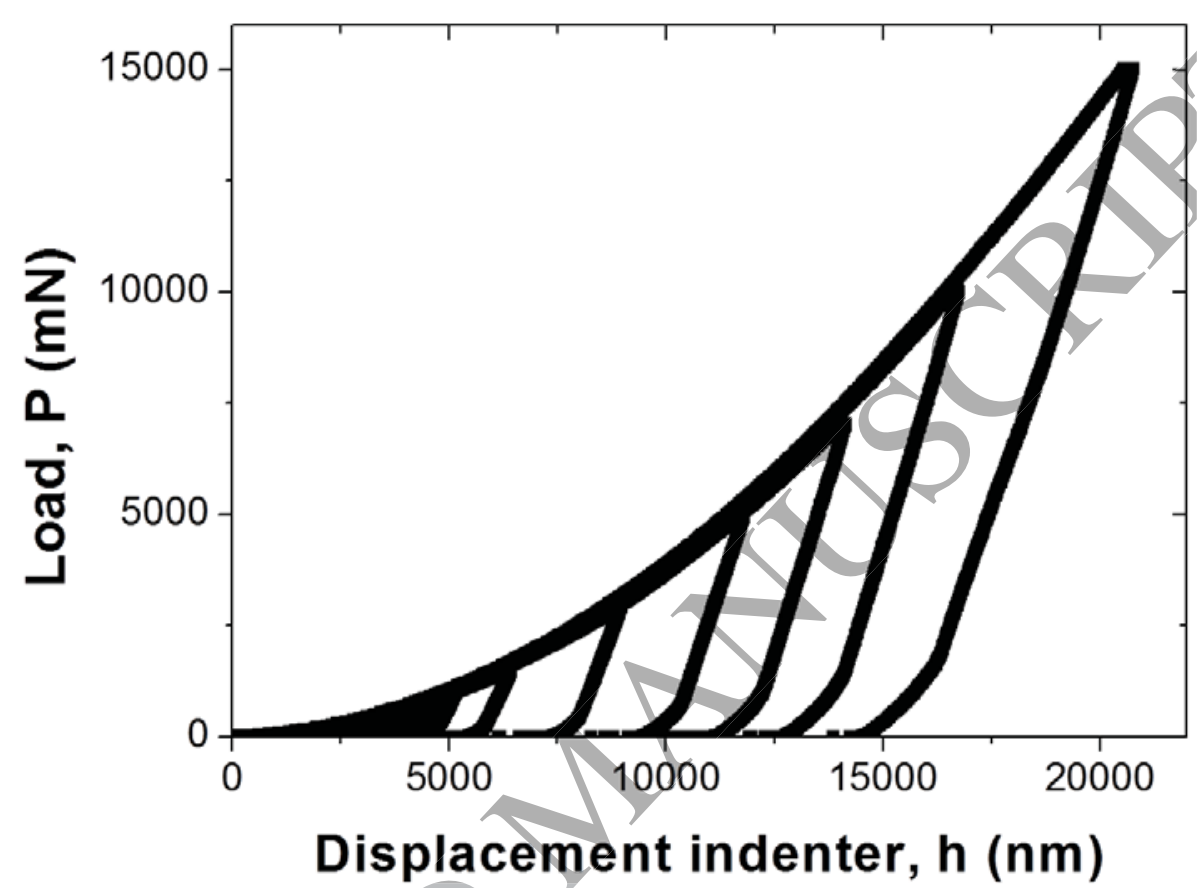

Figure 5. Loading-unloading curves obtained from instrumented indentation test using a Vickers indenter for aluminum 6061-T6.

The two methodologies of Oliver and Pharr (1992) related to sink-in effect and Loubet et al. (1993) for pile-up phenomenon have been applied to the same sets of measurement. The contact area is calculated using Eq. (4) and Eqs. (7a and 7b) according to the mode of deformation around the indent. The corrective factor $\gamma$ has been calculated for each material. Since the compliance term has not a fixed value, the total compliance is plotted versus the inverse of the square root of the contact area to determine this term. Indeed accordingly to Eq. (2), a linear representation must be obtained between the total compliance and the reciprocal square root of the contact area:

$$
C_{T}=C_{f}+\frac{\sqrt{\pi}}{2} \cdot \frac{1}{\beta \gamma} \cdot \frac{1}{E_{R}} \cdot \frac{1}{\sqrt{A_{C}}}
$$

Consequently a linear regression is applied to the experimental data for determining $C_{\mathrm{f}}$ which is the 
intercept at the origin of the straight line. Note that the reduced modulus is determined from the slope of this straight line (Fig. 6).

From Figure 6, it is perceived that $C_{\mathrm{f}}$ has the same value whatever the use of the relationship due to Oliver and Pharr $\left(C_{f}=0.042\right)$ or due to Loubet et al. $\left(C_{f}=0.043\right)$. The same result is observed for all the tested materials. However as it was expected the value of $C_{f}$ differs from each set of the tested materials. The obtained values which are collected in Table 1 are afterwards introduced in Eq. (2) for calculating the reduced modulus.
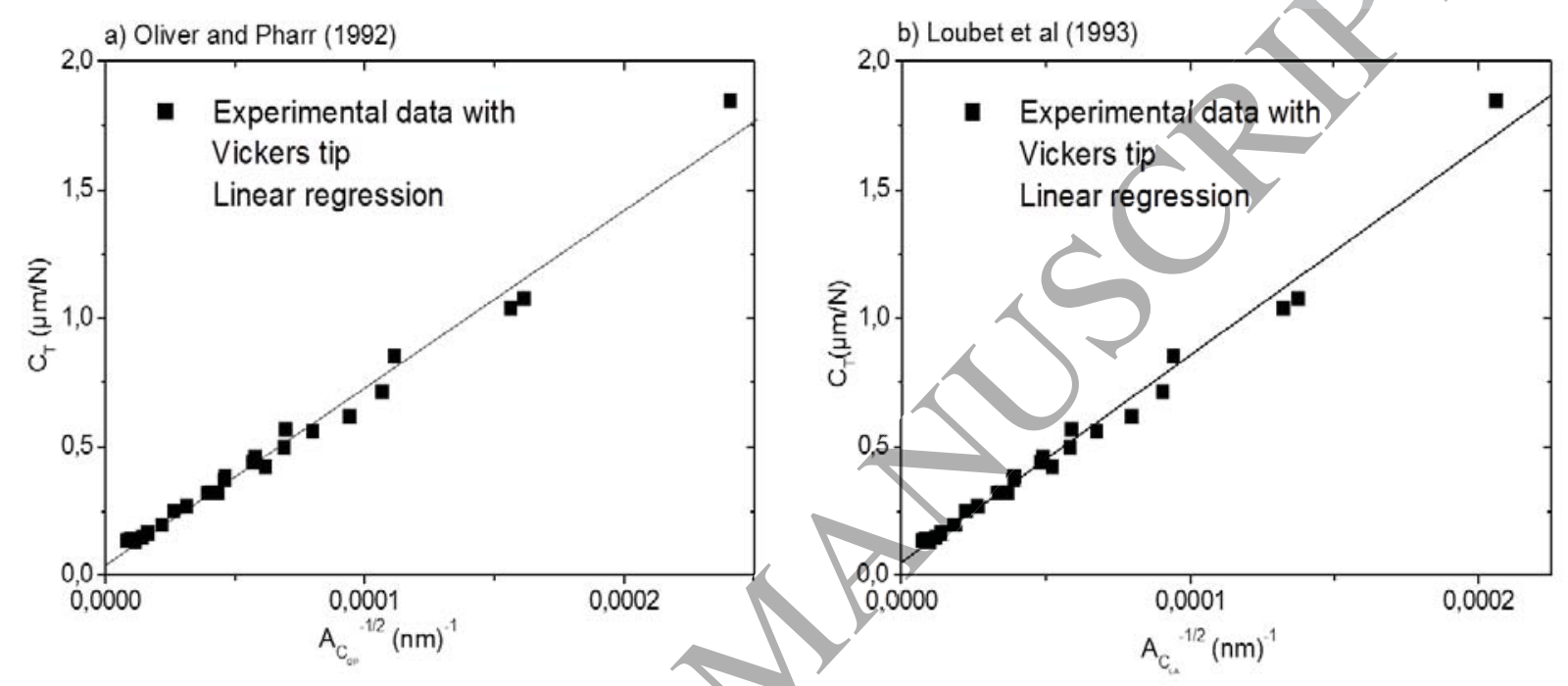

Figure 6. Contact stiffness of brass in function of the inverse of square root of the contact area for Vickers indenter $(a, b)$ indenter following (a) the methodologies of Oliver and Pharr (1992) and (b) Loubet et al.(1993).

Table 1. Frame-compliance, $C_{f}$ in $\mu \mathrm{m} / \mathrm{N}$, the elastic recovery energy to the total work-ofindentation ratio, $U_{E} / U_{T}$, mean values of the depth ratio, $\Delta$, and the deformation mode for the tested materials under Vickers instrumented indentation test.

\begin{tabular}{|c|c|c|c|c|}
\hline Materials & $\mathrm{Cf}(\mu \mathrm{m} / \mathrm{N})$ & $\begin{array}{c}\text { Mode of } \\
\text { deformation }\end{array}$ & $\mathrm{U}_{\mathrm{E}} / \mathrm{U}_{\mathrm{T}}$ & $\Delta$ \\
\hline Low-carbon steel & $0.003 \pm 0.006$ & Pile-up & $0.05 \pm 0.02$ & $0.94 \pm 0.02$ \\
Brass & $0.04 \pm 0.015$ & Pile-up & $0.11 \pm 0.02$ & $0.90 \pm 0.03$ \\
Aluminum & $0.2 \pm 0.01$ & Pile-up & $0.10 \pm 0.01$ & $0.90 \pm 0.02$ \\
Stainless Steel & $0.49 \pm 0.02$ & Pile-up & $0.11 \pm 0.02$ & $0.88 \pm 0.02$ \\
RPSS & $0.12 \pm 0.01$ & --- & $0.17 \pm 0.02$ & $0.83 \pm 0.02$ \\
$\beta-\mathrm{TCP}$ & $0.26 \pm 0.03$ & Sink-in & $0.47 \pm 0.05$ & $0.72 \pm 0.01$ \\
$\mathrm{~T}_{\mathrm{i}} \mathrm{B}_{2}-60 \% \mathrm{~B}_{4} \mathrm{C}$ & $0.11 \pm 0.01$ & Sink-in & $0.52 \pm 0.04$ & $0.44 \pm 0.1$ \\
\hline
\end{tabular}


In a previous investigation, the authors determined the deformation mode by using a depth criterion $\Delta$ representing the ratio of the final depth to the corrected maximum indentation depth (Yetna et $\boldsymbol{a l}$., 2015). It was found that $\Delta$ is greater than 0.83 for materials having only the pile-up deformation mode while it is lower than 0.83 for the ones with sink-in and it was suggested that when neither pileup nor sink-in are dominant in the deformation mode, $\Delta$ equal to 0.83 could then be considered as a criterion to precise the limiting situation between a governing sink-in and a predominant pile-up. A summary of the values of $\Delta$ obtained for Vickers indenter are presented in Table 1.

Following this methodology, it is possible to distinguish the deformation mode as it is indicated in Table 1. The knowledge of the deformation mode allows to select the adequate methodology for calculating the hardness and the elastic modulus, i.e. the methodology of Oliver and Pharr (1992) for sink-in and the methodology of Loubet et al. (1993) for pile-up. In order to compare with the results obtained by applying the methodology of Choi et al. (2004), the elastic recovery energy to the total work-of-indentation ratio $\left(U_{\mathrm{E}} / U_{\mathrm{T}}\right)$ has been calculated and given in Table 1. As it can be seen, when the ratio $U_{E} / U_{T}$ is lower than 0.15 , the deformation mode is pile-up whereas for higher values than 0.25, it is sink-in. This result agrees with the results presented in Fig. 2 due to Choi et al. (2004) and, more largely, with the results obtained for Vickers indentation of common materials. Indeed, sink-in is commonly observed for high values of (UE/UT) ratio. Contrarily, except for few materials like annealed pure metals, pile-up is commonly observed for low values of (UE/UT) ratio. Consequently, it can be reasonably assumed that the parameter $\kappa$ mentioned in Eq. (14) takes the value of 7.30 for the aluminum, brass, low-carbon steel and the rolled stainless steel samples and the value of 5.17 for the two ceramics. In contrast, for the rapid prototyping stainless steel (RPSS) for which no predominant deformation mode were observed, it is not possible to select one value compared to the other, i.e. 5.17 or 7.3, and this is why in the following, it is suggested the use of these two coefficients. The elastic reduced modulus of the tested materials is then calculated by applying Eq. (14) considering the hardness HIT (by the methodology of Oliver and Pharr) and the plastic hardness HP (by work-of-indentation). Table 2 gives the contact hardness HIT and the reduced modulus $E_{I T}$ when applying the methodology of Oliver and Pharr and the plastic hardness HP and the elastic modulus $E_{P}$ by work-of-indentation. For information, Table 2 also collects the values of the Poisson's ratio and the reduced modulus, $E_{\text {RTh }}$ calculated from Eq. (3) using the standard elastic modulus value of the tested materials. 
Table 2. Contact hardness $\mathrm{H}_{\mathrm{IT}}$ and reduced modulus $\mathrm{E}_{\mathrm{IT}}$, plastic hardness HP and reduced modulus $E_{\mathrm{p}}$ for the tested materials. The theoretical values of $E_{R t h}$ are given for comparison (http://www.engineeringtoolbox.com/young-modulus-d 417.html; Yetna et al., 2015; Chicot et al., 2013).

\begin{tabular}{|c|c|c|c|c|c|c|}
\hline Methodology & \multicolumn{2}{|c|}{ Oliver and Pharr } & \multicolumn{2}{|c|}{ Work-of-indentation } & \multirow[b]{2}{*}{$v$} & \multirow{2}{*}{$\begin{array}{c}E_{\text {RTh }} \\
(\mathrm{GPa})\end{array}$} \\
\hline Materials & $E_{I T}(G P a)$ & HIT (GPa) & $E_{p}(G P a)$ & $\mathrm{HP}(\mathrm{GPa})$ & & \\
\hline Low-carbon steel & 192 & 1.3 & 207 & 1.4 & 0.30 & 184 \\
\hline Brass & 74 & 1.2 & 49 & 0.8 & 0.33 & 102 \\
\hline Aluminum & 96 & 1.3 & 88 & 1.2 & 0.34 & 73 \\
\hline Stainless Steel & 207 & 2.8 & 192 & 2.6 & 0.30 & 192 \\
\hline $\operatorname{RPSS}(\kappa=7.30)$ & 236 & 5.5 & 253 & 5.9 & 0.30 & 165 \\
\hline $\operatorname{RPSS}(\kappa=5.17)$ & 167 & 5.5 & 179 & 5.9 & 0.30 & 165 \\
\hline$\beta-\mathrm{TCP}$ & 90 & 8 & 191 & 17 & & 152 \\
\hline $\mathrm{T}_{i} \mathrm{~B}_{2}-60 \% \mathrm{~B}_{4} \mathrm{C}$ & 447 & 45 & 596 & 60 & 0.24 & 358 \\
\hline
\end{tabular}

From Table 2, it is noted that the elastic modulus is different when it is considered the contact hardness HIT with the methodology of Oliver and Pharr or the plastic hardness HP using the work-ofindentation approach and also it slightly differs from the theoretical values of the elastic modulus. It is thought that this discrepancy comes from the definition of the hardness and the influence of the tip defect on the computation of the plastic hardness as it is demonstrated in (Chicot et al., 2015). To avoid this mismatch in the determination of the elastic modulus, it is suggested expressing the elastic energy to total work-of-indentation ratio only as a function of the elastic modulus.

\subsection{An improved relation for computing reduced modulus.}

It was mentioned above that the relationship between the elastic recovery energy to the total workof-indentation ratio and the hardness to reduced modulus ratio was based on numerical simulations under the assumption of perfectly rigid indenter and instrument. From the combination of Eq. (1) and Eq. (2), it can be possible to express the hardness as a function of the reduced modulus, the maximum applied load and of the two compliance terms, $C_{\mathrm{T}}$ and $C_{\mathrm{f}}$, related to the whole indentation system and the instrument frame, respectively, as follows:

$$
H=\frac{4 \cdot \beta^{2} \gamma^{2}}{\pi} \cdot P_{\max }\left(C_{T}-C_{f}\right)^{2} \cdot E_{R}^{2}
$$

The relationship (19) is very interesting since it allows the computation of the hardness without the determination of the contact area which often requires the calibration of the indentation test in order to take into account the influence of the tip defect. By introducing Eq. (19) into Eq. (14), the ratio 
$\left(U_{E} / U_{T}\right)$ is expressed only as a function of the reduced modulus and some parameters which can be easily deduced from the analysis of the unloading part of a load-depth curve. Finally, it is obtained the following equation:

$$
\frac{U_{E}}{U_{T}}=1-\frac{U_{P}}{U_{T}}=\kappa \cdot \frac{4 \cdot \beta^{2} \gamma^{2}}{\pi} \cdot P_{\max }\left(C_{T}-C_{f}\right)^{2} \cdot E_{R}
$$

Where $\beta$ is equal to 1.05. $\gamma$ is only Poisson's coefficient dependent (Hay et al., 1999). $\kappa$ is equal to 5.17 when $\left(U_{E} / U_{T}\right)$ is higher than 0.25 and equals to 7.3 when $\left(U_{E} / U_{T}\right)$ is lower than 0.15 .

For the rapid prototyping stainless steel (RPSS) for which no predominant deformation has been observed and for which $\left(U_{E} / U_{T}\right)$ is close to the limit value of 0.2 , the value of $k$ is undetermined according to (Choi et al., 2004). In order to circumvent any arbitrary choice, the microindentation of the RPSS material is simulated for determining the exact value of $\kappa$. The material properties used in the simulation have been identified by inverse analysis method described in the previous section. Table 3 collects the yield stress, $\sigma_{Y}$, and the work-hardening exponent, $n$, which have been determined from an inverse analysis while elastic modulus $E$ and Poisson's ratio $v$ was taken from the literature (Yetna et al., 2015).

Table 3. Mechanical properties of the rapid prototyping stainless steel (RPSS) used in the finite elements method analysis, i.e. the elastic modulus $E$, the Poisson's ratio $v$, the yield stress $\sigma_{Y}$ and the work hardening exponent $n$.

\begin{tabular}{|c|c|c|c|c|}
\hline Material & $\begin{array}{c}\text { Elastic modulus } \\
\mathrm{E}(\mathrm{GPa})\end{array}$ & $\begin{array}{c}\text { Poisson's ratio } \\
v\end{array}$ & $\begin{array}{c}\text { Yield stress } \\
\sigma_{\mathrm{Y}}(\mathrm{MPa})\end{array}$ & $\begin{array}{c}\text { Work-hardening } \\
\text { Exponent } \mathrm{n}\end{array}$ \\
\hline Rapid prototyping stainless steel & 175 & 0.3 & 540 & 0.39 \\
\hline
\end{tabular}

Figure 7 shows the comparison between the experimental load-depth curve and the simulated response deduced from finite element simulation obtained for the rapid prototyping stainless steel. 


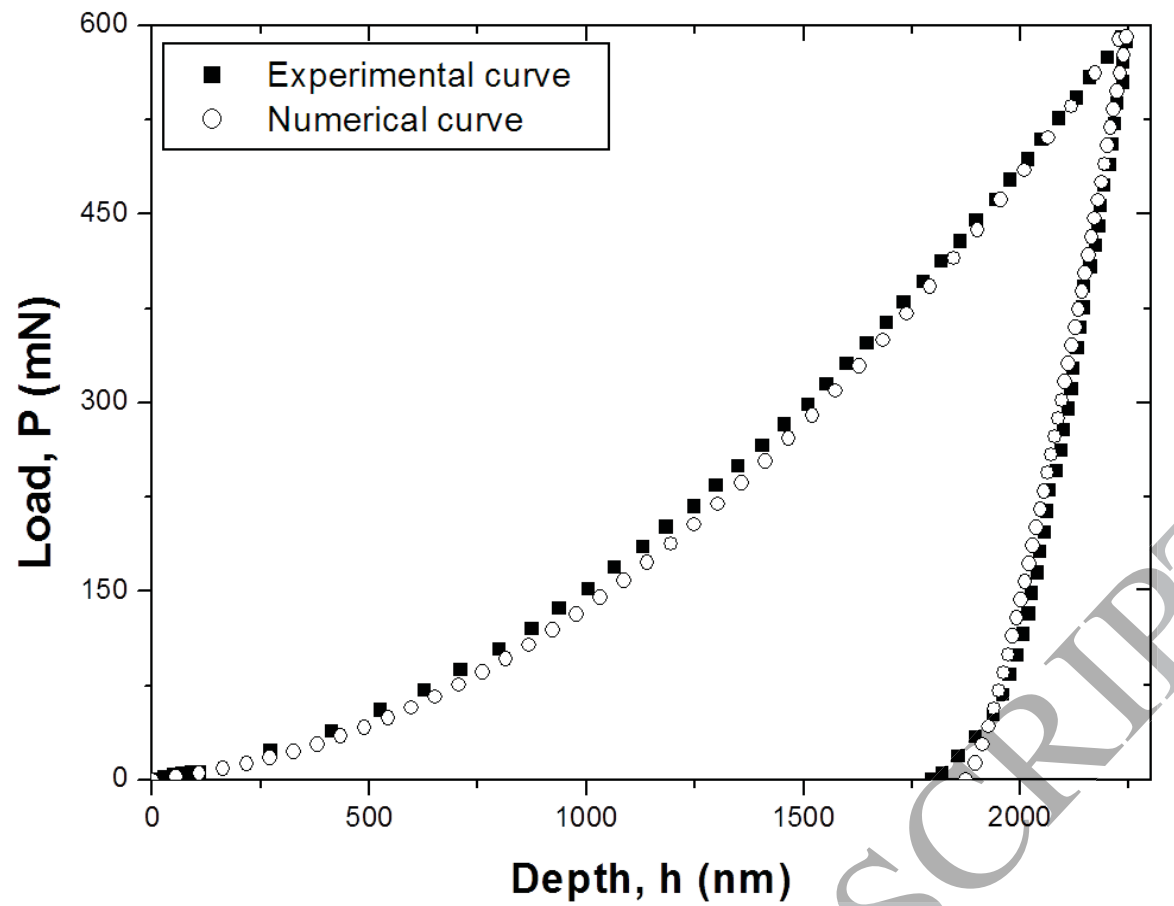

Figure 7. Comparison between the results obtained from the FEM analysis and from the experimental analysis of indentation performed on the rapid prototyping stainless steel.

A good agreement was found between the predictive curve by FEM analysis and the experimental data. From the load-depth curve obtained numerically, the ratio $\left(U_{E} / U_{T}\right)$ and $\left(H I T / E_{T T}\right)$ was calculated. The results obtained have been resumed in Table 4. A value of 6.6 was found for the ratio between $\left(U_{E} / U_{T}\right)$ and $\left(H I T / E_{R}\right)$ thus confirming the theory since this value is clearly located between 5.17 and 7.3.

Table 4. Reduced elastic modulus, hardness, elastic recovery energy, total work-of-indentation and numerical value of the proportionality factor $\kappa$ obtained for the Rapid Prototyping Stainless Steel.

\begin{tabular}{|c|c|c|c|c|c|c|c|}
\hline Material & $\mathrm{E}_{R}(\mathrm{GPa})$ & $\mathrm{HIT}(\mathrm{GPa})$ & $\mathrm{HIT} / \mathrm{E}_{\mathrm{R}}$ & $\mathrm{U}_{\mathrm{E}}(\mathrm{nJ})$ & $\mathrm{U}_{\mathrm{T}}(\mathrm{nJ})$ & $\mathrm{U}_{\mathrm{E}} / \mathrm{U}_{\mathrm{T}}$ & $\kappa$ \\
\hline $\begin{array}{c}\text { Rapid prototyping } \\
\text { stainless steel }\end{array}$ & 165 & 5.25 & 0.032 & 97 & 460 & 0.21 & 6.6 \\
\hline
\end{tabular}

Finally, Eq. (20) is applied to compute the reduced modulus and afterwards the elastic modulus of the tested materials using Eq. (2). Table 5 collects the values of the Poisson's ratio which is used to calculate the corrective coefficient introduced by Hay et al. (1999). The experimental data of the elastic recovery energy to the total work-of-indentation ratio $\left(U_{E} / U_{T}\right)$ and the product of the 
maximum applied load and the compliance term $\left(C_{T}-C_{f}\right)^{2}$ are also shown. Finally the coefficient $\kappa$ is given according to the value of the ratio $\left(U_{E} / U_{T}\right)$ compared to the limit value of 0.2 and the deformation mode, that is to say 7.30 when $\left(U_{E} / U_{T}\right)$ is lower than 0.15 and 5.17 when $\left(U_{E} / U_{T}\right)$ is higher than 0.25. Moreover, since the rapid prototyping stainless steel (RPSS) has a critical value close to this limit value, the calculated value of the elastic modulus is given for the three different conditions of $\kappa$, i.e. $7.3,5.17$ and 6.6 found by finite elements simulation.

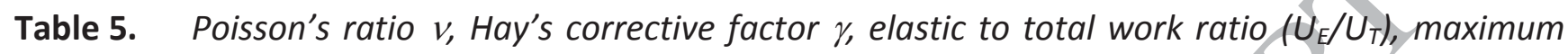
load multiplied by the compliance term $P m .\left(C_{T}-C_{f}\right)^{2}$, factor $\kappa$, elastic modulus calculated from Eq. (20) and the theoretical one for the tested materials.

\begin{tabular}{|c|c|c|c|c|c|c|c|}
\hline Materials & $v$ & $\gamma$ & $\left(\mathrm{U}_{\mathrm{E}} / \mathrm{U}_{\mathrm{T}}\right)$ & $\begin{array}{c}\mathrm{Pm} \cdot\left(\mathrm{C}_{\mathrm{T}}-\mathrm{C}_{\mathrm{f}}\right)^{2} \\
\left.\left(10^{-6} \mathrm{GPa}\right)^{-1}\right)\end{array}$ & $\kappa$ & $\begin{array}{c}E_{W} \\
(\mathbf{G P a})\end{array}$ & $\begin{array}{c}E_{\text {th. }} \\
(\mathrm{GPa})\end{array}$ \\
\hline Low-carbon steel & 0.30 & 1.067 & $0.05 \pm 0.02$ & 23 & 7.30 & $\mathbf{2 0 3}$ & 200 \\
Brass & 0.33 & 1.059 & $0.11 \pm 0.02$ & 90 & 7.30 & $\mathbf{1 0 4}$ & 100 \\
Aluminum & 0.34 & 1.056 & $0.10 \pm 0.01$ & 120 & 7.30 & $\mathbf{6 9}$ & 69 \\
Stainless Steel & 0.30 & 1.067 & $0.11 \pm 0.02$ & 51 & 7.30 & $\mathbf{2 0 1}$ & 200 \\
RPSS & 0.30 & 1.097 & $0.17 \pm 0.02$ & 96 & 7.30 & $\mathbf{1 4 9}$ & 175 \\
RPSS & 0.30 & 1.097 & $0.17 \pm 0.02$ & 96 & 6.60 & $\mathbf{1 6 8}$ & 175 \\
RPSS & 0.30 & 1.097 & $0.17 \pm 0.02$ & 96 & 5.17 & $\mathbf{2 2 4}$ & 175 \\
$\beta$-TCP & 0.30 & 1.067 & $0.47 \pm 0.05$ & 471 & 5.17 & $\mathbf{1 2 3}$ & 160 \\
$\mathrm{~T}_{\mathrm{i}} \mathrm{B}_{2}-60 \% \mathrm{~B}_{4} \mathrm{C}$ & 0.24 & 1.076 & $0.52 \pm 0.04$ & 172 & 5.17 & $\mathbf{4 9 4}$ & 490 \\
\hline
\end{tabular}

It is observed that from Eqs. (20) and (2) allow the determination of the values for the elastic modulus which are in a very good agreement with the values found in literature. For the rapid prototyping stainless steel, it has been considered the three values for $\kappa$ since its value of the ratio $\left(U_{\mathrm{E}} / U_{\mathrm{T}}\right)$ is close to the limit value of 0.2. As it was expected, the best result is given for the intermediate value of $k$ which has been validated by the Finite Element (FE) simulation. However, it was observed a relatively great difference between the elastic modulus determined from Eqs. (20) and (2) and the theoretical value for the $\beta$-TCP bioceramic. This result can be due to the formation of cracks which appear along the diagonals of the indent due to the brittleness of this type of material. Figure 8 confirms the existence of cracks in the extension of the diagonals of the indent and the chipping along the edges of the indent. 


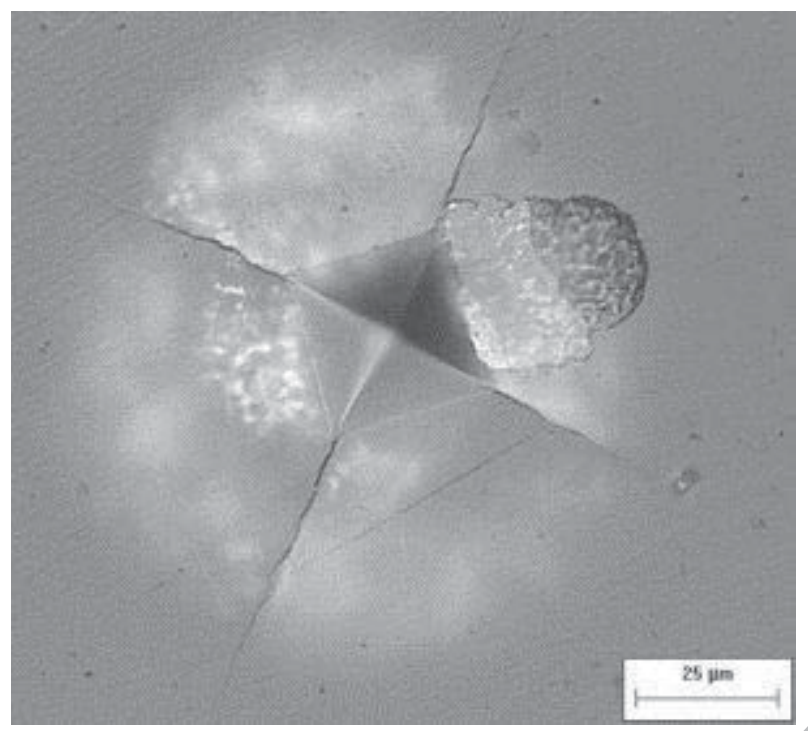

Figure 8. Cracks along the diagonals and chipping close to the edges of the indent resulting from the Vickers indentation load of $5 \mathrm{~N}$ applied into the B-TCP bioceramic (Tricoteaux et al., 2011).

In addition, according to Table 6 it was found that the elastic modulus thus determined from Eqs. (20) and (2) seems to be more accurate than the values found in Yetna et al. (2015) when both Oliver and Pharr (1992) and Loubet et al. (1993) methodologies were applied respectively when sinkin and pile-up mode of deformation occurs.

Table 6. Elastic modulus calculated from Eqs. (20) and (2), using the methodologies of Oliver and Pharr (1992) and Loubet et al. (1993), compared to the theoretical values for the tested materials.

\begin{tabular}{|c|ccccccc|}
\hline Materials & Low-carbon steel & Brass & Aluminum & SS & RPSS & $\beta$-TCP & $\mathrm{T}_{i} \mathrm{~B}_{2}-60 \% \mathrm{~B}_{4} \mathrm{C}$ \\
\hline Loubet et al. (1993) & 208 & 92 & 81 & 212 & 157 & 147 & 481 \\
\hline Oliver and Pharr (1992) & 257 & 111 & 99 & 258 & 190 & 154 & 514 \\
\hline Eqs. (20) and (2) & 203 & 104 & 69 & 201 & 168 & 123 & 494 \\
\hline Theoretical values & 200 & 100 & 69 & 200 & 175 & 160 & 490 \\
\hline
\end{tabular}

\section{Conclusions}

Vickers instrumented indentation tests have been performed on a large variety of materials presenting different mechanical behaviors in terms of elastic modulus to hardness ratio and in terms of deformation mode (pile-up or sink-in mode). For the determination of the elastic modulus, we suggest the application of a relationship where the knowledge of the contact area is not required for 
the computation. The proposed relationship only takes into account the ratio of elastic recovery energy to the total work-of-indentation as well as the maximum load and the total compliance corrected with the frame compliance. For the studied materials, the values obtained for elastic modulus with the proposed relationship were satisfactory except for the material which began to cracking during the indentation process and the results are comparable with the values determined by the methodologies of Oliver and Pharr (1992) or Loubet et al. (1993). Concerning the material presenting cracks, part of the work-of-indentation is used to create and propagate new surfaces owing the cracks along the diagonals of the indent. Consequently, this part of energy is consumed by the initiation and propagation of the cracks and then it influences the computation of the elastic recovery energy to total work-of-indentation ratio. In addition, the value of the proportionality factor of 7.30 for low ratio of energies and 5.17 for higher values was validated and a value of 6.6 was been found by a finite elements method analysis for an intermediate value of the ratio of energies between 0.15 and 0.25 .

\section{References}

ABAQUS. (2003). User's Manual Version 6.5, Hibbit, Karlsson \& Sorensen, Inc.

Alcalá, J., Barone, A. C., Anglada, M., 2000. The influence of plastic hardening on surface deformation modes around Vickers and spherical indents. Acta Materialia. 48(13), 3451-3464.

Alkorta, J., Martínez-Esnaola, J. M., Sevillano, J. G., Malzbender, J., 2006. Comments on “Comment on the determination of mechanical properties from the energy dissipated during indentation" by J. Malzbender [J. Mater. Res. 20, 1090 (2005)]. Journal of Materials Research. 21(01), 302-305.

Antunes, J. M., Menezes, L. F., Fernandes, J. V. (2006). Three-dimensional numerical simulation of Vickers indentation tests. International Journal of Solids and Structures. 43(3-4), 784-806.

Bandyopadhyay, P. R., Chicot, D., Kumar, C. S., Decoopman, X., Lesage, J., 2013. Influence of sinking-in and piling-up on the mechanical properties determination by indentation: A case study on rolled and DMLS stainless steel. Materials Science and Engineering: A. 576, 126-133.

Bartier, O., Hernot, X., Mauvoisin, G. (2010). Theoretical and experimental analysis of contact radius for spherical indentation. Mechanics of Materials, 42(5):640-656.

Bolshakov, A., Oliver, W.C., Pharr G.M. (1996). Influences of stress on the measurement of mechanical properties using nanoindentation: Part II. Finite element simulations. Journal of Materials Research. 11(03), 760-768.

Bulychev S.I., Alekhin V.P., Shorshorov M.Kh., Ternovskii A.P., Shnyrev, G.D., 1975. Determination of Young's modulus according to the indentation diagram. Industrial Lab., 41, 1409-1412.

Chen, J., Bull, S. J., 2009. Relation between the ratio of elastic work to the total work of indentation and the ratio of hardness to Young's modulus for a perfect conical tip. Journal of Materials Research. 24(03), 590-598. 
Chicot, D., de Baets, P., Staia, M. H., Puchi-Cabrera, E. S., Louis, G., Perez Delgado, Y., Vleugels, J., 2013. Influence of tip defect and indenter shape on the mechanical properties determination by indentation of a TiB2-60\%B4C ceramic composite. International Journal of Refractory Metals and Hard Materials. 38(0), 102-110.

Chicot, D., Mendoza, J., Zaoui, A., Louis, G., Lepingle, V., Roudet, F., Lesage, J., 2011. Mechanical properties of magnetite $\left(\mathrm{Fe}_{3} \mathrm{O}_{4}\right)$, hematite $\left(\alpha-\mathrm{Fe}_{2} \mathrm{O}_{3}\right)$ and goethite $(\alpha-\mathrm{FeO}-\mathrm{OH})$ by instrumented indentation and molecular dynamics analysis. Materials Chemistry and Physics. 129(3), 862-870.

Chicot, D., Yetna N'Jock, M., Puchi-Cabrera, E. S., lost, A., Staia, M. H., Louis, G., Aumaitre, R., 2014. A contact area function for Berkovich nanoindentation: Application to hardness determination of a TiHfCN thin film. Thin Solid Films. 558(0), 259-266.

Chicot, D., Yetna N'Jock, M., Roudet, F., Decoopman, X., Staia, M. H., Puchi-Cabrera, E. S., 2015. Some improvements for determining hardness of homogeneous materials from the work-ofindentation. Submitted to Journal of Materials Research.

Choi, Y., Lee, H. S., Kwon, D., 2004. Analysis of sharp-tip-indentation load-depth curve for contact area determination taking into account pile-up and sink-in effects. Journal of Materials Research. 19(11), 3307-3315.

Collin, J.-M., Mauvoisin, G., El Abdi, R., 2008. An experimental method to determine the contact radius changes during a spherical instrumented indentation. Mechanics of Materials. 40(4), 401406.

Doerner M.F., Nix, W.D., 1986. A method for interpreting the data from depth-sensing indentation instruments. J. Mater. Res., 1, 601-609.

Hay, J. C., Bolshakov, A., \& Pharr, G. M., 1999. A critical examination of the fundamental relations used in the analysis of nanoindentation data. Journal of Materials Research. 14(06), 2296-2305.

Hochstetter, G., Jimenez, A., Loubet, J. L., 1999. Strain-rate effects on hardness of glassy polymers in the nanoscale range. Comparison between quasi-static and continuous stiffness measurements. Journal of Macromolecular Science, Part B. 38(5-6), 681-692.

Loubet, J. L., Bauer, M., Tonck, A., Bec, S., Gauthier-Manuel, B., 1993. Nanoindentation with a Surface Force Apparatus. In M. Nastasi, D. Parkin \& H. Gleiter (Eds.), Mechanical Properties and Deformation Behavior of Materials Having Ultra-Fine Microstructures. 233, 429-447.

Loubet, J. L., Georges, J. M., Marchesini, J. M., Meille, G., 1984. Vickers indentation curves of magnesium-oxides. Journal of Tribology. 106, 43-48.

Malzbender, J., 2005. Comment on the determination of mechanical properties from the energy dissipated during Indentation. Journal of Materials Research. 20, 1090-1092.

Malzbender, J., de With, G., den Toonder, J. M. J., 2000. Determination of the elastic modulus and hardness of sol-gel coatings on glass: influence of indenter geometry. Thin Solid Films. 372(12), 134-143.

Mata, M., Alcala, J., 2004. The role of friction on sharp indentation. Journal of the Mechanics and Physics of Solids 52 (1), 145-165.

Modulus of Elasticity or Young's Modulus - and Tensile Modulus for some common Materials. (n.d.). Retrieved November 6, 2015, from http://www.engineeringtoolbox.com/young-modulusd_417.html

O’Neil, H., 1951. Hardness measurements of metals and alloys. Chapman Hall, New Jersey. 
Oliver, W. C., Pharr, G. M. (1992). An improved technique for determining hardness and elastic modulus using load and displacement sensing indentation experiments. Journal of Materials Research. 7(6), 1564-1583.

Oliver, W. C., Pharr, G. M., 2004. Measurement of hardness and elastic modulus by instrumented indentation: Advances in understanding and refinements to methodology. Journal of Materials Research. 19(01), 3-20.

Pharr, G. M., Bolshakov, A., 2002. Understanding nanoindentation unloading curves. Journal of Materials Research. 17(10), 2660-2671.

Quinn, G. D., Patel, P. L., Lloyd, I., 2002. Effect of loading rate upon conventional ceramic microindentation hardness. Journal of Research of the National Institute of Standards and Technology. 107, 299-306.

Sakai, M., 1993. Energy principle of the indentation-induced inelastic surface deformation and hardness of brittle materials. Acta Metallurgica et Materialia. 41(6), 1751-1758.

Stilwell, N. A., Tabor, D., 1961. Elastic recovery of conical indentation. Proceedings of the Physical Society. 78, 169-179.

Tan, M., 2000. A study of indentation work in homogeneous materials. Journal of Materials Research. $15,1209-1212$.

Tensile Modulus-Modulus of Elasticity or Young's Modulus for some common Materials. http://www.engineeringtoolbox.com/young-modulus-d_417.html.

Tricoteaux, A., Rguiti, E., Chicot, D., Boilet, L., Descamps, M., Leriche, A., Lesage, J., 2011. Influence of porosity on the mechanical properties of microporous $\beta$-TCP bioceramics by usual and instrumented Vickers microindentation. Journal of the European Ceramic Society. 31(8), 1361 1369.

Troyon, M., Huang, L., 2006. Comparison of different analysis methods in nanoindentation and influence on the correction factor for contact area. Surface and Coatings Technology. 201(3-4), 1613-1619.

Yang, R., Zhang, T., Feng, Y., 2010. Theoretical analysis of the relationship between hardness, elastic modulus, and the work of indentation for work-hardening materials. Journal of Materials Research. 25, 2072-2077.

Yang, R., Zhang, T., Jiang, P., Bai, Y., 2008. Experimental verification and theoretical analysis of the relationships between hardness, elastic modulus, and the work of indentation. Applied Physics Letters. 92, 231906.

Yetna N'jock, M., Chicot, D., Ndjaka, J. M., Lesage, J., Decoopman, X., Roudet, F., Mejias, A., 2015. A criterion to identify sinking-in and piling-up in indentation of materials. International Journal of Mechanical Sciences. 90(0), 145-150.

Zeng, K., Chiu, C. h., 2001. An analysis of load-penetration curves from instrumented indentation. Acta Materialia. 49(17), 3539-3551. 
Table 1. Frame-compliance, $C_{f}$ in $\mu \mathrm{m} / \mathrm{N}$, the elastic recovery energy to the total work-ofindentation ratio, $\mathrm{U}_{\mathrm{E}} / \mathrm{U}_{\mathrm{T}}$, mean values of the depth ratio, $\Delta$, and the deformation mode for the tested materials under Vickers instrumented indentation test.

Table 2. Contact hardness $\mathrm{H}_{\mathrm{T}}$ and reduced modulus $\mathrm{E}_{\mathrm{IT}}$, plastic hardness HP and reduced modulus $E_{P}$ for the tested materials. The theoretical values of $E_{R t h}$ are given for comparison (http://www.engineeringtoolbox.com/young-modulus-d_417.html; Yetna et al., 2015; Chicot et al., 2013).

Table 3. Mechanical properties of the rapid prototyping stainless steel (RPSS) used in the finite elements method analysis, i.e. the elastic modulus E, the Poisson's ratio $v$, the yield stress $\sigma_{Y}$ and the work hardening exponent $n$.

Table 4. Reduced elastic modulus, hardness, elastic recovery energy, total work-of-indentation and numerical value of the proportionality factor $\kappa$ obtained for the Rapid Prototyping Stainless Steel.

Table 5. Poisson's ratio $v$, Hay's corrective factor $\gamma$, elastic to total work ratio $\left(U_{E} / U_{T}\right)$, maximum load multiplied by the compliance term $\mathrm{Pm} .\left(\mathrm{C}_{\mathrm{T}}-\mathrm{C}_{\mathrm{f}}\right)^{2}$, factor $\kappa$, elastic modulus calculated from Eq. (20) and the theoretical one for the tested materials.

Table 6. Elastic modulus calculated from Eqs. (20) and (2), using the methodologies of Oliver and Pharr (1992) and Loubet et al. (1993), compared to the theoretical values for the tested materials.

Table 1.

\begin{tabular}{|c|c|c|c|c|}
\hline Materials & $\mathrm{Cf}(\mu \mathrm{m} / \mathrm{N})$ & $\begin{array}{c}\text { Mode of } \\
\text { deformation }\end{array}$ & $\mathrm{U}_{\mathrm{E}} / \mathrm{U}_{\mathrm{T}}$ & $\Delta$ \\
\hline Low-carbon steel & $0.003 \pm 0.006$ & Pile-up & $0.05 \pm 0.02$ & $0.94 \pm 0.02$ \\
Brass & $0.04 \pm 0.015$ & Pile-up & $0.11 \pm 0.02$ & $0.90 \pm 0.03$ \\
Aluminum & $0.2 \pm 0.01$ & Pile-up & $0.10 \pm 0.01$ & $0.90 \pm 0.02$ \\
Stainless Steel & $0.49 \pm 0.02$ & Pile-up & $0.11 \pm 0.02$ & $0.88 \pm 0.02$ \\
RPSS & $0.12 \pm 0.01$ & --- & $0.17 \pm 0.02$ & $0.83 \pm 0.02$ \\
$\beta$-TCP & $0.26 \pm 0.03$ & Sink-in & $0.47 \pm 0.05$ & $0.72 \pm 0.01$ \\
$\mathrm{~T}_{\mathrm{i}} \mathrm{B}_{2}-60 \% \mathrm{~B}_{4} \mathrm{C}$ & $0.11 \pm 0.01$ & Sink-in & $0.52 \pm 0.04$ & $0.44 \pm 0.1$ \\
\hline
\end{tabular}


Table 2.

\begin{tabular}{|c|c|c|c|c|c|c|}
\hline Methodology & \multicolumn{2}{|c|}{ Oliver and Pharr } & \multicolumn{2}{|c|}{ Work-of-indentation } & \multirow{2}{*}{$v$} & \multirow{2}{*}{$\begin{array}{c}\mathrm{E}_{\mathrm{RTh}} \\
(\mathrm{GPa})\end{array}$} \\
\hline Materials & $\mathrm{E}_{\mathrm{IT}}(\mathrm{GPa})$ & HIT (GPa) & $E_{P}(G P a)$ & $\mathrm{HP}(\mathrm{GPa})$ & & \\
\hline Low-carbon steel & 192 & 1.3 & 207 & 1.4 & 0.30 & 184 \\
\hline Brass & 74 & 1.2 & 49 & 0.8 & 0.33 & 102 \\
\hline Aluminum & 96 & 1.3 & 88 & 1.2 & 0.34 & 73 \\
\hline Stainless Steel & 207 & 2.8 & 192 & 2.6 & 0.30 & 192 \\
\hline RPSS $(\kappa=7.30)$ & 236 & 5.5 & 253 & 5.9 & 0 & 165 \\
\hline RPSS $(\kappa=5.17)$ & 167 & 5.5 & 179 & 5.9 & 0.30 & 165 \\
\hline$\beta-\mathrm{TCP}$ & 90 & 8 & 191 & 17 & & 152 \\
\hline $\mathrm{T}_{\mathrm{i}} \mathrm{B}_{2}-60 \% \mathrm{~B}_{4} \mathrm{C}$ & 447 & 45 & 596 & 60 & 0.24 & 358 \\
\hline
\end{tabular}

Table 3.

\begin{tabular}{|c|c|c|c|c|}
\hline Material & $\begin{array}{c}\text { Elastic modulus } \\
\mathrm{E}(\mathrm{GPa})\end{array}$ & $\begin{array}{c}\text { Poisson's ratio } \\
\text { V }\end{array}$ & $\begin{array}{c}\text { Yield stress } \\
\sigma_{\mathrm{Y}}(\mathrm{MPa})\end{array}$ & $\begin{array}{c}\text { Work-hardening } \\
\text { Exponent } \mathrm{n}\end{array}$ \\
\hline $\begin{array}{c}\text { Rapid prototyping } \\
\text { stainless steel }\end{array}$ & 175 & 0.3 & 540 & 0.39 \\
\hline
\end{tabular}

Table 4.

\begin{tabular}{|c|c|c|c|c|c|c|c|}
\hline Material & $\mathrm{E}_{\mathrm{R}}(\mathrm{GPa})$ & $\mathrm{HIT}(\mathrm{GPa})$ & $\mathrm{HIT} / \mathrm{E}_{\mathrm{R}}$ & $\mathrm{U}_{\mathrm{E}}(\mathrm{nJ})$ & $\mathrm{U}_{\mathrm{T}}(\mathrm{nJ})$ & $\mathrm{U}_{\mathrm{E}} / \mathrm{U}_{\mathrm{T}}$ & $\kappa$ \\
\hline $\begin{array}{c}\text { Rapid prototyping } \\
\text { stainless steel }\end{array}$ & 165 & 5.25 & 0.032 & 97 & 460 & 0.21 & 6.6 \\
\hline
\end{tabular}

Table 5.

\begin{tabular}{|c|c|c|c|c|c|c|c|}
\hline Materials & $V$ & $\gamma$ & $\left(\mathrm{U}_{\mathrm{E}} / \mathrm{U}_{\mathrm{T}}\right)$ & $\begin{array}{c}\mathrm{Pm} \cdot\left(\mathrm{C}_{\mathrm{T}}-\mathrm{C}_{\mathrm{f}}\right)^{2} \\
\left(10^{-6} \mathrm{GPa}^{-1}\right)\end{array}$ & $\kappa$ & $\begin{array}{c}E_{W} \\
(\mathbf{G P a})\end{array}$ & $\begin{array}{c}\mathrm{E}_{\text {th. }} \\
(\mathrm{GPa})\end{array}$ \\
\hline Low-carbon steel & 0.30 & 1.067 & $0.05 \pm 0.02$ & 23 & 7.30 & $\mathbf{2 0 3}$ & 200 \\
Brass & 0.33 & 1.059 & $0.11 \pm 0.02$ & 90 & 7.30 & $\mathbf{1 0 4}$ & 100 \\
Aluminum & 0.34 & 1.056 & $0.10 \pm 0.01$ & 120 & 7.30 & $\mathbf{6 9}$ & 69 \\
Stainless Steel & 0.30 & 1.067 & $0.11 \pm 0.02$ & 51 & 7.30 & $\mathbf{2 0 1}$ & 200 \\
RPSS & 0.30 & 1.097 & $0.17 \pm 0.02$ & 96 & 7.30 & $\mathbf{1 4 9}$ & 175 \\
RPSS & 0.30 & 1.097 & $0.17 \pm 0.02$ & 96 & 6.60 & $\mathbf{1 6 8}$ & 175 \\
RPSS & 0.30 & 1.097 & $0.17 \pm 0.02$ & 96 & 5.17 & $\mathbf{2 2 4}$ & 175 \\
$\beta$ B-TCP & 0.30 & 1.067 & $0.47 \pm 0.05$ & 471 & 5.17 & $\mathbf{1 2 3}$ & 160 \\
$\mathrm{~T}_{\mathrm{i}} \mathrm{B}_{2}-60 \% \mathrm{~B}_{4} \mathrm{C}$ & 0.24 & 1.076 & $0.52 \pm 0.04$ & 172 & 5.17 & $\mathbf{4 9 4}$ & 490 \\
\hline
\end{tabular}


Table 6.

\begin{tabular}{|c|ccccccc|}
\hline Materials & Low-carbon steel & Brass & Aluminum & SS & RPSS & $\beta$-TCP & $\mathrm{T}_{i} \mathrm{~B}_{2}-60 \% \mathrm{~B}_{4} \mathrm{C}$ \\
\hline Loubet et al. (1993) & 208 & 92 & 81 & 212 & 157 & 147 & 481 \\
\hline Oliver and Pharr (1992) & 257 & 111 & 99 & 258 & 190 & 154 & 514 \\
\hline Eqs. (20) and (2) & 203 & 104 & 69 & 201 & 168 & 123 & 494 \\
\hline Theoretical values & 200 & 100 & 69 & 200 & 175 & 160 & 490 \\
\hline
\end{tabular}

